\title{
Reducing violence on a secure ward
}

\author{
Ann Mortimer
}

\begin{abstract}
Prediction of in-patient poychiatric violence is difficult: longltudinal appraisal during environmental change may identity influential factors. Incidents on a secure ward fell substantially in number and severity over 31 months during which stafl were trained in control and restraint techniques (CAR) and a monthly oudit of incidents was carried out. A fow patients caused many incidents. Women were disproportionately violent: both sexes preferred a victim of the same gender. Most incidents occurred in clusters by the same patient. Percelved ontecedents were patients' poychosis, Incodequate CaR and other staff. Increasing CaR staff wos the only factor associated with reducing violence. Patients attacked each other rather than nurses as violence decreased.
\end{abstract}

At least one in ten psychiatric patients assaults staff (DHSS, 1988). Assaults may be underreported (Haller \& Deluty, 1988) and increasing (James et al, 1990). Although many studies describe antecedents and correlates of patient violence, Aquilina (1991) found antecedents to be non-specific and of little predictive value. Violence is the end product of innumerable factors: upbringing, personality, age, sex, diagnosis, current symptomatology and finally the situation of the moment. Clinically, 'rules of thumb' tend to be followed, with extra risks perceived in previously violent patients, particularly if young, male and psychotic.

The inherent variability of patients may be allowed for by studying violence levels over time in the context of environmental change. I report a study of violence over 31 months, during which all ward staff were trained in control and restraint techniques $(C \& R)$ and a monthly audit of incidents was carried out.

\section{The study}

A 12-bed secure ward, accepting patients who could not be safely or adequately cared for on open acute wards, was studied prospectively for 31 months. The catchment population was approximately 500000; no patient was informal. Initially five of 23 nurses (11) registered mental nurses) were trained in C\&R techniques for the safe management of violent patients, including three instructors who taught their colleagues over the next 29 months.

For each violent incident the identity, sex, age and ICD-9 (World Health Organization, 1978) diagnosis of the perpetrator, and identity and sex of the victim were documented, plus perceived antecedents and observed consequences. A monthly audit meeting aimed to identify if and how each incident could have been avoided, with particular reference to current patient management policies. Incidents were assigned a category (Fottrell, 1980).

(a) Near miss. No physical assault (property/ good luck/successful control and restraint): score 2.

(b) Assault. Patient struck victim, no sequelae. Excludes head: score 5.

(c) Serious assault. Sequelae present or blows to head: score 10 .

(d) Life threatening assault. Weapons, strangulation, fractures, sick leave: score 20.

The sum of scores (allocated arbitrarily after initial discussions) gave an overall index of the 'volume' of violence each month.

\section{Findings}

The ward was invariably full. Turnover of patients was about 30 per year; staff turnover was negligible. Thirty-eight patients perpetrated 178 incidents. Thirty-two had a schizophrenic psychosis $(87 \%)$, five manic depressive psychosis and one personality disorder. Paranoid schizophrenia was not associated with greater frequency or severity of incidents.

Twenty-six patients were male and 12 female. Women were responsible for $55 \%$ of incidents in spite of being only $32 \%$ of 
perpetrators. The female mean age, 39 years, was significantly higher than the male, 30 years $(t=-2.13, P=0.04)$.

There was a clear same gender preference: the most common incident involved a female patient attacking another female (68), followed by a male patient attacking another male (45). Incidents in which a female patient attacked a male or a male patient attacked a female were less frequent, 18 and 17 respectively. This is statistically significant (cross tabulation $x^{2}=39.3, P=0.001$ ).

A minority of 'outlier' patients was identified: four female and two male patients (15\%) accounted for 100 incidents (62\%). All had schizophrenia. Sixty-four per cent of incidents occurred as part of a cluster, i.e. a patient repeated violent behaviour, usually over a few hours, at least once before further incidents by different patients took place. Prevention of clusters would have reduced incidents by $58 \%$.

To test a suggestion (Rusius, 1992) that 'minor violence' by vulnerable patients follows more serious acts by more violent patients, a number of 'runs' tests were performed (varying aggregation and dichotomisation) comparing the severity of clusters with subsequent incidents by different patients prior to the next cluster. The hypothesis predicted a non- random sequence with many runs; however, no analysis produced a sequence with probability less than 0.18 .

Severely psychotic, disturbed mental states were most frequently implicated at audit (Table 1) followed by inadequate staffing or non-availability of a C\&R team. Unmet patients' demands and interpersonal provocation were habitual. Less common issues were staff behaviour and specific situations. Audit led to some changes of policy (Table 2). All were in place by seven months.

A plot of incidents, violence score and control and restraint staff each month over 31 months is shown in Fig. 1. Violence fell after month 14 with lower, less variable scores. The Spearman correlation coefficient of date with score was $0.47(P=0.01)$. Possible explanations included the following:

(a) Absence of outliers. The number of months during which outliers were on the ward was summed before and after month 15. There were 38 'outlier months' in each period: absence of outliers seems an unlikely explanation.

(b) Accumulation of C\&R trained staff. C\&R cannot be implemented without a team of 3': the turning point appears soon

Table 1. Perceived antecedents/contributory factors to incidents

\begin{tabular}{ll}
\hline Antecedent/contributory factor identtied at audit & Number of mentions \\
\hline Severely psychotic agitated state of patient & 58 \\
Inadequate staffing or unable to mount C\&R team & 26 \\
Patient demanding cigarettes, money, food, etc. & 11 \\
'Nuisance' behaviour by other patients provoked incident & 10 \\
Patients allowed in staff office & 6 \\
Patients' access to potential weapons & 5 \\
Patient demanding to leave & 4 \\
Staff too permissive, allowed situation to escalate & 4 \\
Visiting time altercations & 4 \\
\hline
\end{tabular}

Table 2. Perceived antecedents/contributory factors to incidents: policy changes and their timing

\begin{tabular}{ll}
\hline Pollcy & When started \\
\hline All nursing and medical staff to have full C\&R training & month 1 \\
Assessment of dangerousness prior to admission & month 1 \\
Urgent review of patients repeating incidents & month 2 \\
Observe patients arguing and intervene early & month 3 \\
Patients not allowed in staff office & month 3 \\
Patients' fitness to recelve visitors to be routinely reviewed & month 4 \\
Consider l:1 nursing by staff of opposite gendertsame gender chaperone & month 5 \\
Nurses always to be within sight or hearing of their colleagues & month 5 \\
\hline
\end{tabular}




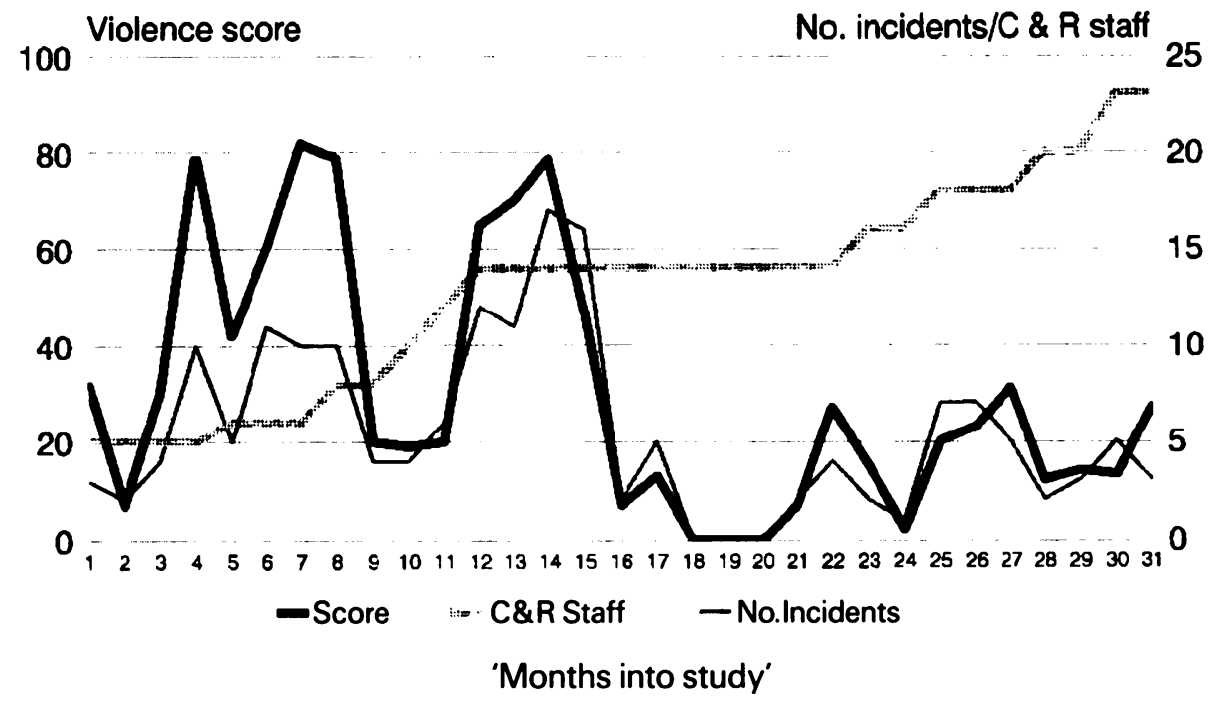

Fig. 1. Number of incidents, violence scores and C\&R staff levels over time

after 14 staff were trained, which would allow a 'team of 3' at all times.

(c) Lessening of incident severity. A crosstabulation of incident categories in the first 10 months with the final 10 months of the study (Table 3) suggests that serious and life threatening assaults fell in the second period at the same time as an increase in near misses (mostly when the C\&R team had successfully intervened). The probability that time period and incident category were independent was very small $\left(\chi^{2}=13.4, P=0.004\right)$.

Victim identity changed towards the end of the study. Fourteen per cent of victims were not nurses in the first 10 months: this had risen to $40 \%$ in the final 10 months. A $\chi^{2}$ test on the cross-tabulation of time period and victim identity showed a highly significant interaction between these two variables $\left(\chi^{2}=6.8, P=0.009\right)$. Most non-nurse victims were other patients. Mean incident score did not differ between nurse and patient victims during either period.

\section{Comment}

The predominance of patients with schizophrenia, $87 \%$, is higher than previously reported on open wards, for example $41 \%$ (Lim et al, 1991). Schizophrenia may lower the threshold for transfer to a secure ward if patients are seen as more violent than other diagnostic groups. Conversely the threshold for transfer of female patients may be high if secure wards are thought to be an undesirable setting for women. This could exclude all but the most disturbed women, accounting for their disproportionate aggression. An interaction between female gender and ageing in reducing violence (Haller \& Deluty, 1988) is not consistent with the higher age of these patients, whose severe disorder may have dampened the social discouragement of violence supposedly impinging on women more than men as both age (Feshbach, 1970). Same gender preference in choice of victim may be swayed in men by perceived social disapproval of attacking unrelated women, and in women by men's superior strength.

Table 3. Assaults are less serious during the later part of the study

\begin{tabular}{llllll}
\hline Period & Near miss & Assault & Serious assault & Lte threatening aseaulf & Total \\
\hline First ten months & $13(21 \%)$ & $21(33 \%)$ & $26(41 \%)$ & $3(5 \%)$ & $63(100 \%)$ \\
Final ten months & $23(50 \%)$ & $15(33 \%)$ & $7(15 \%)$ & $1(2 \%)$ & $46(100 \%)$ \\
\hline
\end{tabular}

$\chi^{2}=13.4, P=0.004$. 
The findings of Tobin et al (1991) of 19\% patients responsible for $57 \%$ incidents, and Powell et al (1994) of $8 \%$ responsible for $40 \%$, are highly consistent with these results. Accurate documentation and summary of incidents in case-notes is probably the most useful predictor of in-patient violence. Predominance of clusters suggests more intensive responses to an initial incident, with the specific objective of avoiding repetition.

Audit may be recommended to any unit where violence is a problem. Identification of poor staffing and training assisted arguments for adequate resources, and contradicted the unfortunate notion that being assaulted by patients is a routine part of psychiatric nursing. This study is the first, as far as I am aware, to document a reduction in number and severity of violent incidents. The accumulation of $C \& R$ expertise is a plausible explanation, assisted by new policies for patient assessment, observation and management. Transfer of patients to more secure facilities remained a rare event throughout this study. The increase in attacks on patients rather than nurses contrasts with previous reports (Noble \& Rodger, 1989). This trend is worrying, but there was no evidence that patients were injured more often or severely than before.

The Code of Practice to the Mental Health Act (Department of Health and Welsh Office, 1993) states, "Staff in NHS hospitals and private nursing homes who are ordinarily likely to find themselves in situations where control and restraint might be necessary should attend an appropriate course run by a qualified instructor". Moreover, the Management of Health and Safety at Work regulations (Health and Safety Executive, 1992) require hospitals to assess health and safety risks to employees, patients and visitors. Measures resulting from this risk assessment must be recorded, including adequate safety training so staff are "capable enough at their jobs to avoid risks".

Misgivings about inappropriate use of $C \& R$ techniques to discipline patients may be obviated through good supervision, particularly by instructors. The overriding impression from this audit was that greater confidence of nurses, both in general and in dealing with incidents, was noticed by patients and may have deterred violence. If correct, this has important implications for the training, development and, perhaps most crucially, the morale of psychiatric nurses.

\section{Acknowledgements}

I am grateful to Ian Carter, Michelle Ginty, Sean Fitzgerald, Patricia Jessop, Michael Poulter and Gary Ward.

\section{References}

Agumuna, C. (1991) Violence by psychiatric inpatients. Medicine, Science and The Law, 31, 306-312.

DEPARTMENT OF HEALTH AND SOCIAL SECURTY (1988) Violence to staff. Report of the DHSS advisory committee on violence to staff. London: DHSS.

DEPARTMENT OF HEALTH AND WELSH OFFICE (1993) Code of Practice to the Mental Health Act 1983. London: HMSO. 77.

FESHBACH, S. (1970) Aggression. In Carmichael's Manual of Child Psychology, Vol. II (ed. P. H. Mussen). New York: Wiley.

FotTREL. E. (1980) A study of violent behaviour among patients in psychiatric hospitals. British Journal of Psychiatry. 136, 216-221.

HALER, R. M. \& DELTY. R. H. (1988) Assaults on staff by psychiatric inpatients. A critical review. British Joumal of Psychiatry. $182.174-179$.

HEALTH AND SAFETY EXECUTIVE (1992) New Health and Safety at Work Regulations. Sheffield: Health and Safety Executtve.

James, D. V., Fineberg, N. A., Shah, A. K. Priest, R. G. (1990) An increase in violence on an acute psychiatric ward. British Journal of Psychiatry. 166. 846-852.

LiM. L., ToBIN, M. \& FAlkowskl. W. (1991) The characteristics of patients who display violent behaviour in a psychiatric hospital. British Journal of Clinical and Social Psychiatry. 8, 12-18.

NOBLE, P. \& RODGER, S. (1989) Violence by psychiatric inpatients. British Journal of Psychiatry. 168, 384-390.

POWEu, G., CANN, W. \& CrowE, M. (1994) What events precede violent incidents in psychiatric hospitals? British Journal of Psychiatry. 166. 107-1 12.

Rusius, C. W. (1992) The effect environmental change has on the frequency of violent incidents. Psychiatric Bulletin. 16, 489-490.

TOBIN, M., LM, L. \& FALKOwSK1, W. (1991) How do we manage violent behaviour? British Joumal of Clinical and Social Psychiatry. 8. 19-23.

WORLD Health OGanization (1978) Mental Disorders: Glossary and Guide to their Classification in Accordance with the Ninth Revision of the International Classification of Diseases (ICD-9). Geneva: WHO.

Ann M. Mortimer, Senior Lecturer in Psychiatry, Charing Cross and Westminster Medical School: formerly Consultant Psychiatrist, Huddersfield Health Authority, Yorkshire

Correspondence c/o West London Healthcare NHS Trust, Uxbridge Road, Southall, Middlesex UB1 3EU 